\title{
Effect of Alzheimer Caregiving on Circulating Levels of C-Reactive Protein and Other Biomarkers Relevant to Cardiovascular Disease Risk: A Longitudinal Study
}

\author{
Roland von Känel ${ }^{\mathrm{a}, \mathrm{b}}$ Paul J. Mills ${ }^{\mathrm{b}}$ Brent T. Mausbach ${ }^{\mathrm{b}}$ Joel E. Dimsdale ${ }^{\mathrm{b}}$ \\ Thomas L. Patterson $^{b}$ Michael G. Ziegler ${ }^{c}$ Sonia Ancoli-Israel ${ }^{b}$ \\ Matthew Allison ${ }^{d}$ Elizabeth A. Chattillion ${ }^{\mathrm{e}}$ Igor Grant ${ }^{\mathrm{b}}$ \\ a Division of Psychosomatic Medicine, Department of General Internal Medicine, Inselspital, Bern University \\ Hospital and University of Bern, Bern, Switzerland; Departments of b Psychiatry, ${ }^{\mathrm{C}}$ Medicine and d Family and \\ Preventive Medicine, University of California San Diego, La Jolla, Calif., and 'San Diego State University/University \\ of California, San Diego Joint Doctoral Program in Clinical Psychology, San Diego, Calif., USA
}

\section{Key Words}

Alzheimer's disease • Biomarkers • Cardiovascular disease • Caregiver $\cdot$ Cytokines $\cdot$ Inflammation $\cdot$ Psychological stress

\begin{abstract}
Background: Providing care to a spouse with Alzheimer's disease (AD) may contribute to cardiovascular disease (CVD). The acute phase reactant C-reactive protein (CRP) is a wellestablished biomarker of an increased CVD risk. Objective: To investigate the hypothesis that dementia caregiving is associated with elevated circulating levels of CRP and possibly other biomarkers of CVD risk. Methods: We examined 118 elderly spousal Alzheimer caregivers and 51 noncaregiving controls about once a year for up to 3 years. Random regression models with fixed and time-variant effects for a range of covariates known to affect biomarker levels were used to evaluate changes in CRP and in 12 additional measures of inflammation, cellular adhesion, endothelial function, and hemostasis in relation to caregiving status, years of caregiving, and major transitions in the caregiving situation. $\boldsymbol{R e}$ sults: During the study period, longer duration of caregiving
\end{abstract}

\section{KARGER}

(C) 2011 S. Karger AG, Basel

Fax +4161306 1234

E-Mail karger@karger.ch

www.karger.com
Accessible online at: www.karger.com/ger was associated with elevated CRP levels $(p=0.040)$ and caregivers showed greater tumor necrosis factor (TNF)- $\alpha$ levels than controls $(p=0.048)$. Additionally, 3 months after the death of the $A D$ spouse, caregivers showed a significant drop in CRP levels $(p=0.003)$ and levels of soluble intercellular adhesion molecule (sICAM)-1 ( $p=0.008)$. Conclusion: Duration of caregiving and being a caregiver per se were both associated with chronic low-grade inflammation as indicated by elevated CRP and TNF- $\alpha$ levels, respectively. Conversely, death of the AD spouse was associated with lower CRP and sICAM-1 levels. The findings indicate that chronic caregiving of those with dementia may result in increased inflammation and, thereby, possibly increased CVD risk.

Copyright $\odot 2011$ S. Karger AG, Basel

\section{Introduction}

Evidence to date suggests that in addition to compromising mental health, providing informal care to a spouse with Alzheimer's disease (AD) also takes its toll on caregivers' physical health, particularly the cardiovascular 
system [1-4; for review]. Relative to their noncaregiving counterparts, AD caregivers have a higher risk of developing incident coronary heart disease (CHD) [5].

Stressors and distress associated with caregiving have been linked to key mechanisms of the initiation, propagation, and clinical manifestation of atherothrombotic diseases. For instance, duration of $\mathrm{AD}$ caregiving was associated with endothelial dysfunction [6] and carotid intima-media thickness [7]. Dementia severity of the care recipient was also related to impaired endothelial function and enhanced coagulation activity in the caregiver $[6,8]$. High negative affects (including depression), low positive affects, sleeping difficulties, and low subjective health are commonly found in caregivers $[2,3,9,10]$, and these factors may also increase the risk of cardiovascular disease (CVD) [11]. In dementia caregivers, depressive symptoms shortened the time to incident CVD [12], and relative to noncaregiving controls, $\mathrm{AD}$ caregivers showed associations between poor sleep and inflammation [i.e. IL-6 and C-reactive protein (CRP)] [13], and between role overload and reduced fibrinolytic capacity over time [14].

In terms of sociodemographic factors, male AD caregivers showed a higher risk of developing CHD than female caregivers [15]. Atherosclerotic burden seems particularly high in older AD caregivers, as there is an agerelated increase in coagulation (i.e. fibrin $\mathrm{D}$-dimer levels) [16] and inflammatory markers (i.e. IL-6) [17]. Low socioeconomic status, defined as low education level, was associated with greater dementia caregiver burden than higher education [18].

In addition, major transitions in the caregiving situation, such as placement of the AD spouse in a long-term care facility or death of the AD spouse, showed associations with a drop in caregivers' D-dimer levels starting half a year after the transition; this effect was accompanied by a decrease in depressive symptoms and role overload [19]. Biological changes due to increased sympathoadrenal medullary (SAM) arousal might partially link caregiving stress with the atherosclerotic mechanisms delineated above [20, 21].

Although traditional risk factors are increased in $\mathrm{AD}$ caregivers $[22,23]$ and mediate some of the CHD risk in this group [15], many patients at-risk for CHD cannot be identified solely on the basis of traditional CVD risk factors alone [24]. This has prompted an intense search for circulating biomarkers to improve CVD risk prediction [25]. In this regard, the acute phase reactant CRP is probably the most established biomarker of increased CVD risk $[26,27]$, which may directly affect expression of cel- lular adhesion molecules, impact fibrinolysis, and impair endothelial function [25]. Moreover, it has been demonstrated that high-sensitivity CRP (but no other cardiovascular biomarkers) adds prognostic information on $\mathrm{fu}$ ture CVD risk above and beyond the Framingham CHD risk score [28], particularly in individuals aged 65 years and older [29].

In addition to CRP, slightly elevated levels of several markers of inflammation [e.g. tumor necrosis factor (TNF)- $\alpha$, interferon- $\gamma$, IL-6, IL-8, IL-10, IL-12], endothelial dysfunction [e.g. endothelin-1, von Willebrand factor (VWF)], upregulated cellular adhesion [e.g. soluble intercellular adhesion molecule (sICAM)-1, soluble vascular cellular adhesion molecule (sVCAM)-1], and hemostasis (e.g. fibrin D-dimer, plasminogen activator inhibitor-1) have also been shown to be involved in atherosclerosis and to predict the risk of incident CHD and poor prognosis in patients with established CHD [30-41]. Notably, the predictive value of biomarkers for CVD risk is largely independent of sociodemographic, lifestyle, and traditional CVD risk factors.

Given this information, the primary aim of this study was to investigate the longitudinal relationship between measures of $\mathrm{AD}$ caregiving and the most established biomarker of increased CVD risk, high-sensitive CRP. Our specific hypothesis was that CRP would be higher in spousal $\mathrm{AD}$ caregivers compared to noncaregiving controls, and show a direct association with the duration of caregiving and a drop following a major transition in the caregiving situation. Secondary analyses were performed with several additional cardiovascular biomarkers as outcomes to explore whether these would add important information above and beyond that obtained from the CRP analysis. In the analysis, and because these covariates may variously affect the concentrations of biomarkers including CRP [28, 42], we controlled a priori for sociodemographic factors (i.e. age, gender, education), traditional cardiovascular risk factors, medication, and diseases, as well as physical symptomatology, lifestyle factors (i.e. alcohol consumption, physical activity), role overload, affect, and subjective sleep quality. Some of these covariates were also found to partially account for the relationship between caregiving stress and biomarker levels, such as age $[15,16]$ and sleep [13]. Therefore, in case of a significant association between biomarkers and caregiver status, duration of caregiving, or transitions in the caregiving situation, we explored whether covariates, which differentiated caregivers from controls at study entry, would moderate or mediate these relationships. 


\section{Materials and Methods}

\section{Study Participants and Design}

We recruited community-dwelling spousal AD caregivers and noncaregiving married controls into the University of California, San Diego (UCSD) 'Alzheimer's Caregiver Study' which is investigating health consequences of dementia caregiving stress. Participants were referred from the UCSD Alzheimer's Disease Research Center, agencies serving caregivers, local senior citizen health fairs, community support groups, and other participants. Caregivers and controls were matched in terms of age ( $\geq 55$ years) and gender. Exclusion criteria were current major illnesses (e.g. cancer), severe hypertension (blood pressure exceeding 200/120 $\mathrm{mm} \mathrm{Hg}$ ), and medications affecting biomarker levels, including oral anticoagulants, nonselective $\beta$-blockers, and steroids. As the prevalence of daily aspirin use is about $30 \%$ in community-dwelling US adults aged 65 years or older [43], aspirin intake was not an exclusion criterion, but treated as a control variable.

Participants underwent in-home assessments every 12 months for a period of up to 3 years (i.e. for a maximum of 4 visits). Every 3 months, research staff also made follow-up phone calls to check for changes in health status and in caregiver transitions (i.e. placement of the AD spouse in a long-term care facility or death of the $\mathrm{AD}$ spouse), and participants were additionally asked to call research staff when these transitions occurred. Post-transition assessments were set up at 3, 15, and 27 months after the transition. For all assessments, a research nurse gathered sociodemographic, medical, and psychosocial data using questionnaires. Participants kept their daily routine and were thus not required to fast for the collection of blood for the biomarker assessment. Blood was collected between 10:00 and 10:45 a.m.

Out of the total enrolment of 186 study participants, 5 noncaregivers whose spouse had died during the study period and 12 participants with some missing baseline data were excluded from the present study. This yielded a final sample of 169 subjects (118 caregivers, 51 controls). All participants provided written informed consent to the study protocol that was approved by the UCSD Institutional Review Board.

\section{Demographic and Health Assessment}

Sociodemographic Factors. We collected information on age, gender, ethnicity, years of education (reflecting socioeconomic status), years of caregiving, and hours of care per day.

Medical Data. Participants were asked whether a doctor had informed them that they currently have or have ever had any CVD (comprising myocardial infarction, congestive heart failure, angina, additional heart diseases, and stroke/transient ischemic attack) or diabetes. They were also provided a list of 21 health symptoms (e.g. sore throat, skin rash, toothache) to indicate how many of these they had experienced in the last month. For the assessment of subjective health, all participants were asked to rate their health in general, using a 5-point Likert scale ranging from 0 ('excellent') to 4 ('poor'). BMI was calculated based on subjects' self report of weight and height. Plasma low-density lipoprotein cholesterol (LDL-C) and high-density lipoprotein cholesterol (HDLC) levels were determined by standard methodology at the clinical chemistry laboratories of the UCSD Medical Center. The LDL-C/ HDL-C ratio was computed and used for statistical analysis. After a 15-min resting period, the research nurse collected three systolic and diastolic blood pressure measurements using a noninva- sive Microlife Blood Pressure monitor. The average mean arterial pressure (MAP) was computed to be used in statistical analysis. Prescribed cholesterol- and blood pressure-lowering medications, aspirin, and antidepressants were also noted.

Lifestyle Factors. Smoking status was defined as ever smoker (i.e. former or current smoking) versus never smoker (only 3 participants smoked at baseline). The Rapid Assessment of Physical Activity scale was used to assess the amount of physical activity at light, moderate, and vigorous intensities in a typical week (score: 0-6) [44]. Alcohol consumption in the last month was assessed by multiplying the number of days participants drank alcohol by the number of alcoholic drinks they usually drank on those days (score: 0-36).

Sleep. We assessed subjective sleep quality with the interviewer-administered Pittsburg Sleep Quality Index comprising 19 items yielding a global score between 0 and 21 [45]. Higher scores indicate poorer sleep quality.

Affect. We used the Positive and Negative Affect Scale to assess the level of negative and positive mood in the last few weeks [46]. Participants rated 10 mood items for negative affect (e.g. irritable, nervous, hostile) and positive affect (e.g. excited, proud, active), each on a 5 -point scale ( 1 = very slightly or not at all, $5=$ extremely; score 10-50 for either scale).

Role Overload. We used Pearlin's Role Overload scale [47] to assess the extent to which caregivers and controls felt overwhelmed by life's responsibilities. The scale consists of 4 items rated from 1 (not at all) to 4 (completely; total score between 4 and 16), e.g. 'you work hard (as a caregiver) but never seem to make any progress'. The sections in parentheses specific to caregivers were excluded in the questionnaires given to controls.

Dementia Severity. Caregivers were interviewed using the Clinical Dementia Rating scale [48]; they indicated dementia symptoms of their spouses in 6 domains: (1) memory, (2) orientation, (3) judgment and problem solving, (4) community affairs, (5) home and hobbies, and (6) personal care. Based on item responses, an overall dementia severity score is given $(0=$ no dementia, $1=$ mild dementia, $2=$ moderate dementia, and $3=$ severe dementia).

\section{Biomarkers}

Circulating concentrations of biomarkers were determined in duplicates from EDTA plasma samples stored at $-80^{\circ} \mathrm{C}$. Concentrations of biomarkers were determined in duplicates using commercially available enzyme-linked immunosorbent assays per the manufacturers' instructions (Meso Scale Discovery, Gaithersburg, Md., USA: CRP, TNF- $\alpha$, IL-6, IL-8, IL-10, IL-12p70, interferon- $\gamma$, sICAM-1, sVCAM-1; Quantikine, R\&D Systems, Minneapolis, Minn., USA: endothelin-1; Asserachrom Stago, Asnières, France: VWF antigen, plasminogen activator inhibitor-1, $\mathrm{D}$-dimer). Intra- and interassay coefficients of variation were $<10 \%$ for all biomarkers.

\section{Data Analysis}

Data were analyzed using PASW 18.0 statistical software package (SPSS Inc., Chicago, Ill., USA). Two-tailed level of significance was set at $\mathrm{p}<0.05$. To approximate a normal distribution, all biomarker values were $\log _{10}$-transformed and values 3 SDs above the mean $\log _{10}$ transformed value were deleted as outliers ( 1 outlier for interferon- $\gamma$ and sVCAM-1, 2 outliers for CRP and TNF- $\alpha, 3$ outliers for endothelin-1, 4 outliers for IL-12p70 
and IL-8, 6 outliers for IL-10, 7 outliers for IL-6). One VWF value $<15 \%$ was deleted because of suspected VWF disease. Independent-samples $t$ test and $\chi^{2}$ test were used to compare caregivers and noncaregivers on baseline characteristics. Pearson's correlation coefficient was computed to estimate the zero-order association between two variables.

We conducted a mixed (random effects) regression analysis to examine the impact of caregiver status (i.e. caregivers vs. noncaregiving controls), years of caregiving, and caregiver transitions (i.e. placement and death of the AD spouse) on circulating levels of biomarkers over time. We made adjustments for sociodemographic, medical, lifestyle, and psychosocial factors, all of which might have affected the concentrations of the various biomarkers. Mixed-model regression is a powerful analysis that allows one to estimate an intercept and slope for each participant based on all available data for that individual (i.e. even when some data points are missing), augmented by the data from the entire sample [49]. Our primary outcome was the change in CRP levels over time. Secondary analyses were performed with all other biomarkers as outcomes. Effect sizes are expressed as pseudo- $\mathrm{R}^{2}$ which indicates the amount of variance of the outcome that is explained by a model's specific combination of independent variables [49].

To increase the interpretability of regression coefficients and to diminish problems associated with multicollinearity, we centered independent variables before conducting analysis [50], except for 'time' (i.e. the number of assessments) which was linear in nature with the baseline assessment coded as ' 0 '. Controlling for 'time' may be important because with an increasing number of assessments, anticipatory arousal elicited by the unfamiliarity with the testing protocol and its probable effects on biomarker levels may decrease. Linear variables were centered around their grand means. Dummy-coded categorical variables were centered at -0.5 (e.g. noncaregivers) and +0.5 (e.g. caregivers). Because the dependent variables were log-transformed values, several regression coefficients would be very small if using the original scaling of independent variables. Therefore, to provide estimates that can be interpreted, we express estimates for variables marked below with an '*) per change in 3 units (i.e. we divided the values of these variables by 3 before being entered into the multivariate model).

The model included the following fixed effects: age*, gender, education*, CVD (yes/no), diabetes (yes/no), number of health symptoms ${ }^{*}$, subjective health, BMI*, LDL-C/HDL-C ratio, MAP*, cholesterol-lowering medication (yes/no), blood pressure-lowering medication (yes/no), aspirin (yes/no), antidepressant medication (yes/no), smoking status, physical activity, alcohol consumption $^{*}$, sleep quality*, negative affect ${ }^{*}$, positive affect ${ }^{*}$, role overload, caregiving status, years caregiving, placement status of the $\mathrm{AD}$ spouse (yes/no), and deceased status of the AD spouse (yes/ no). Of these, age, CVD, diabetes, the number of health symptoms, subjective health, $\mathrm{BMI}, \mathrm{LDL}-\mathrm{C} / \mathrm{HDL}-\mathrm{C}$ ratio, $\mathrm{MAP}$, medication categories, smoking status, physical activity, alcohol consumption, sleep quality, negative affect, positive affect, role overload, years caregiving, and caregiving transitions were all entered as time-varying. Random intercepts were modeled for participants. A significant effect of placement or death of the AD spouse would mean a change in the intercept of a biomarker (e.g. CRP levels) as a function of the transition (i.e. from pre- to post-transition). In case of a significant main effect for caregiver status, years caregiving, and caregiving transitions, we probed for interactions of these variables with covariates which significantly dif- ferentiated caregivers from controls at baseline. For significant interactions, we applied the Holmbeck method [51] to test whether high levels (+1 SD from the mean) versus low levels ( -1 SD from the mean) of a continuously scaled moderator variable would alter the association of caregiver status, years caregiving, and caregiving transitions with biomarker concentrations.

The 169 subjects contributed a total of 483 assessments (mean of 2.9 assessments per participant). Data for all of the fixed-effect variables were complete in $100 \%$ of assessments per the study design. Time-variant variables were complete in $100 \%$ of the assessments for medication categories, physical activity, and transitions in the caregiving situation; in $98.3 \%$ for years caregiving; in $98.1 \%$ for sleep quality; in $97.9 \%$ for CVD, health symptoms, subjective health, BMI, smoking status, alcohol consumption, and role overload; in $97.7 \%$ for diabetes and positive and negative affects; in 93.8\% for LDL-C/HDL-C ratio, and in $93.0 \%$ for MAP. After deleting outliers, biomarker values were available in $87.4 \%$ (CRP) to $94.6 \%(\mathrm{TNF}-\alpha)$ of all assessments.

\section{Results}

\section{Characteristics of Study Participants at Baseline}

The mean age \pm SD of all the participants was $75 \pm$ 8 years (range: $55-90$ ), 68\% were women, and 92\% were Caucasians. Caregivers had been providing care to their AD spouse for an average of $4.4 \pm 3.4$ years (range: $0.5-$ 17.1). Caregivers spent $7.4 \pm 5.8 \mathrm{~h}$ per day (range: $1-24$ ) caring for their spouse. The mean Clinical Dementia Rating total score of the care recipients was $1.64 \pm 0.59$ (range: 1-3), indicating mild-to-moderate dementia (only 7 AD spouses had severe dementia).

Table 1 shows the baseline characteristics of caregivers and controls. Compared to controls, caregivers had expectedly more physical symptomatology, worse subjective health and sleep, more negative affect and role overload, and less positive affect. Except for lower physical activity in caregivers, there were no significant group differences in other cardiovascular risk factors, as well as in medications and sociodemographic variables.

Table 2 gives circulating levels of biomarkers at the baseline assessment as well as intercorrelations among the individual biomarkers. Elevated CRP levels were associated with greater levels of measures of endothelial dysfunction (i.e. endothelin-1, VWF antigen, sICAM-1, and sVCAM-1), as well as impaired fibrinolysis (i.e. plasminogen activator inhibitor-1), and IL-6 (i.e. a potent stimulant of liver CRP production).

\section{Transitions in the Caregiving Situation}

Over the course of the study, 30 caregivers (25.4\%) placed their spouse in a long-term care facility and 20 (16.9\%) experienced the death of their spouse. The initial 
Table 1. Baseline sociodemographic and health characteristics of 169 study participants

\begin{tabular}{|c|c|c|c|}
\hline Variables & $\begin{array}{l}\text { Caregivers } \\
(\mathrm{n}=118)\end{array}$ & $\begin{array}{l}\text { Noncaregivers } \\
(\mathrm{n}=51)\end{array}$ & $\mathrm{p}$ \\
\hline Age, years & $74.4(8.1)$ & $74.4(5.9)$ & 0.963 \\
\hline Female gender, $\%$ & 70.3 & 64.7 & 0.469 \\
\hline Education, years & $15.2(3.1)$ & $15.7(3.2)$ & 0.286 \\
\hline $\mathrm{CVD}, \%$ & 16.9 & 9.8 & 0.345 \\
\hline Diabetes, \% & 12.7 & 3.9 & 0.099 \\
\hline Number of health symptoms & $1.96(2.04)$ & $0.84(1.38)$ & $<0.001$ \\
\hline Subjective health score & $2.48(0.90)$ & $3.10(0.90)$ & $<0.001$ \\
\hline BMI & $26.6(4.8)$ & $26.5(6.2)$ & 0.929 \\
\hline LDL-C, mg/dl & $106.1(34.9)$ & $105.3(26.9)$ & 0.888 \\
\hline $\mathrm{HDL}-\mathrm{C}, \mathrm{mg} / \mathrm{dl}$ & $52.2(15.9)$ & $53.3(16.7)$ & 0.686 \\
\hline LDL-C/HDL-C ratio & $2.16(0.82)$ & $2.17(0.91)$ & 0.945 \\
\hline Systolic blood pressure, $\mathrm{mm} \mathrm{Hg}$ & $134.6(15.3)$ & $133.9(16.1)$ & 0.801 \\
\hline Diastolic blood pressure, $\mathrm{mm} \mathrm{Hg}$ & $75.9(8.6)$ & $73.9(10.5)$ & 0.206 \\
\hline MAP, mm Hg & $95.4(9.6)$ & $93.2(11.2)$ & 0.370 \\
\hline Cholesterol-lowering medication, $\%$ & 46.6 & 41.2 & 0.515 \\
\hline Blood pressure-lowering medication, \% & 60.2 & 54.9 & 0.523 \\
\hline Aspirin, \% & 27.1 & 31.4 & 0.573 \\
\hline Antidepressant medication, $\%$ & 25.4 & 21.6 & 0.591 \\
\hline Ever smoker, \% & 45.8 & 37.3 & 0.305 \\
\hline Physical activity score & $3.41(1.66)$ & $4.06(1.58)$ & 0.018 \\
\hline Alcohol consumption score & $5.53(5.81)$ & $5.98(6.30)$ & 0.649 \\
\hline Pittsburgh Sleep Quality Index score & $6.62(3.53)$ & $4.37(2.47)$ & $<0.001$ \\
\hline Negative affect score & $17.9(6.1)$ & $13.7(5.4)$ & $<0.001$ \\
\hline Positive affect score & $31.9(7.5)$ & $37.5(5.8)$ & $<0.001$ \\
\hline Role overload score & $5.14(3.20)$ & $1.35(2.04)$ & $<0.001$ \\
\hline
\end{tabular}

Data are given as means (SD) or percentages.

post-transition assessments occurred at 3 months following placement or death of the $\mathrm{AD}$ spouse. The remaining assessments took place approximately 12 months (12 placements, 10 deaths) or 24 months (3 placements, 1 death) later.

\section{Changes in CRP Levels}

Significant zero-order associations between several key potential confounding variables and CRP levels emerged over time. Higher CRP levels were associated with lower education $(r=-0.10, p=0.037)$, more health symptoms $(\mathrm{r}=0.10, \mathrm{p}=0.045)$, poorer subjective health $(\mathrm{r}=-0.22, \mathrm{p}<0.001)$, less physical activity $(\mathrm{r}=-0.12, \mathrm{p}=$ $0.014)$, and greater negative affect $(r=0.15, p=0.003)$. No significant associations were seen between CRP and age, gender, alcohol consumption, sleep quality, positive affect, and role overload.

Table 3 shows the multivariate model for CRP levels. More years of caregiving (but not caregiver status per se) were associated with higher CRP levels over time ( $\mathrm{p}=$ 0.040 ; explained variance $=1.21 \%$ ). Figure la shows the increase in CRP levels across 5-year steps of caregiving duration. In caregivers who had been providing care to their $\mathrm{AD}$ spouse for 15 years, mean CRP levels were predicted to be twofold higher [1.43 mg/l (95\% CI: 0.73-2.79)] than in caregivers who were at the beginning of their caregiver career [0.71 mg/l (95\% CI: 0.42-1.20)] and in noncaregiving controls [0.74 mg/l (95\% CI: $0.40-1.36)$ ], respectively, if all other covariates were held constant in the model.

In addition, CRP levels had significantly dropped at 3 months after the death of the AD spouse $(\mathrm{p}=0.003$, explained variance $=2.15 \%$ ). Figure $1 \mathrm{~b}$ illustrates that caregivers whose spouse had died had 60\% lower mean CRP levels than those who continued to provide care for their spouse [0.53 mg/l (95\% CI: $0.26-1.08)$ vs. $1.33 \mathrm{mg} / \mathrm{l}(95 \%$ CI: 0.92-1.93)].

The association between longer duration of caregiving and CRP increase over time $(0.019 \pm 0.008, \mathrm{p}=$ 
Table 2. Baseline concentrations and intercorrelations of biomarkers

\begin{tabular}{|c|c|c|c|c|c|c|c|c|c|c|c|c|}
\hline Biomarker & TNF- $\alpha$ & INF- $\gamma$ & IL-12 & IL-6 & IL-8 & IL-10 & ET-1 & VWF:Ag & sICAM-1 & sVCAM-1 & D-dimer & PAI-1 \\
\hline $\begin{array}{l}\mathrm{CRP}, \mathrm{mg} / \mathrm{l} \\
3.22 \pm 5.70\end{array}$ & 0.04 & -0.10 & 0.11 & $0.29^{* * * *}$ & $-0.22^{* *}$ & 0.16 & $0.25^{* *}$ & $0.18^{*}$ & $0.53^{* * *}$ & $0.61^{* * *}$ & $-<0.01$ & $0.21^{*}$ \\
\hline $\begin{array}{l}\text { TNF- } \alpha, p g / m l \\
5.96 \pm 2.37\end{array}$ & - & 0.13 & 0.05 & $0.27^{* * *}$ & $0.58^{* * *}$ & 0.14 & -0.06 & -0.07 & 0.06 & 0.02 & 0.11 & 0.13 \\
\hline $\begin{array}{l}\text { INF- } \gamma, \mathrm{pg} / \mathrm{ml} \\
1.95 \pm 1.67\end{array}$ & & - & 0.14 & $<0.01$ & $0.29^{* * *}$ & $0.19^{*}$ & $-0.21^{*}$ & $-0.26^{* *}$ & $-0.16^{*}$ & $-0.19^{*}$ & $<0.01$ & 0.16 \\
\hline $\begin{array}{l}\mathrm{IL}-6, \mathrm{pg} / \mathrm{ml} \\
1.56 \pm 1.75\end{array}$ & & & & - & 0.04 & 0.12 & $0.20^{*}$ & 0.05 & $0.26^{* *}$ & $0.28^{* * *}$ & 0.09 & $0.16^{*}$ \\
\hline $\begin{array}{l}\text { IL-8, pg/ml } \\
7.09 \pm 3.85\end{array}$ & & & & & - & -0.09 & $-0.33^{* * *}$ & $-0.27^{* * *}$ & $-0.38^{* * *}$ & $-0.48^{* * *}$ & -0.01 & $0.18^{*}$ \\
\hline $\begin{array}{l}\text { VWF:Ag, \% } \\
176.1 \pm 115.3\end{array}$ & & & & & & & & - & $0.30^{* * *}$ & $0.34^{* * *}$ & $0.17^{*}$ & 0.09 \\
\hline $\begin{array}{l}\text { sICAM-1, ng/ml } \\
360.1 \pm 209.3\end{array}$ & & & & & & & & & - & $0.89^{* * *}$ & 0.01 & 0.05 \\
\hline $\begin{array}{l}\text { sVCAM- } 1, \mathrm{ng} / \mathrm{ml} \\
652.2 \pm 346.5\end{array}$ & & & & & & & & & & - & 0.04 & 0.02 \\
\hline $\begin{array}{l}\text { D-dimer, } \mathrm{ng} / \mathrm{ml} \\
788.1 \pm 473.9\end{array}$ & & & & & & & & & & & - & -0.10 \\
\hline $\begin{array}{l}\mathrm{PAI}-1, \mathrm{ng} / \mathrm{ml} \\
35.0 \pm 30.5\end{array}$ & & & & & & & & & & & & - \\
\hline
\end{tabular}

Data are given as means \pm SD for biomarker levels and Pearson correlation coefficients with significance level $\left({ }^{*} \mathrm{p}<0.05 ;{ }^{* *} \mathrm{p}<0.01 ;{ }^{* * *} \mathrm{p}<0.001\right)$ for intercorrelations between log-transformed values of biomarkers. ET = Endothelin; INF = interferon; PAI = plasminogen activator inhibitor; VWF:Ag = von Willebrand factor antigen.

0.014), as well as the drop in CRP levels after spousal death $(-0.242 \pm 0.109, \mathrm{p}=0.028)$, were also significant without making adjustments for covariates. The significance of both these associations further persisted when baseline characteristics that differentiated between caregivers and controls (i.e. number of health symptoms, subjective health, physical activity, sleep quality, negative affect, positive affect, and role overload) were added separately to the model, thereby suggesting that there were no mediational effects (data not shown). In the fully adjusted model, baseline characteristics differentiating caregivers from controls also did not turn out to be effect moderators, as they did not significantly interact with years of caregiving and spousal death in determining CRP levels (data not show).

Dementia Caregiving and Cardiovascular Biomarkers

\section{Changes in Levels of Other Biomarkers}

As can be seen in tables 3 and 4, years of caregiving were not significantly associated with levels of any additional biomarker. However, caregivers showed greater TNF- $\alpha$ levels over time than noncaregiving controls $(\mathrm{p}=$ 0.048 , explained variance $=0.94 \%$ ); this association was also significant without covariate adjustment $(0.054 \pm$ $0.021, \mathrm{p}=0.010)$. Figure $1 \mathrm{c}$ shows that caregivers had $15.7 \%$ greater mean TNF- $\alpha$ levels over time than noncaregiving controls. This effect was not significantly mediated or moderated by baseline characteristics that differentiated between caregivers and controls (data not shown).

In terms of caregiving transitions, placement of the $\mathrm{AD}$ spouse in a long-term care facility was not signifi- 
Table 3. Changes over time in circulating levels of CRP and cytokines

\begin{tabular}{|c|c|c|c|c|c|c|c|}
\hline Variables entered & $\begin{array}{l}\mathrm{CRP} \\
\mathrm{mg} / \mathrm{l}\end{array}$ & $\begin{array}{l}\text { TNF- } \alpha \\
\mathrm{pg} / \mathrm{ml}\end{array}$ & $\begin{array}{l}\text { Interferon- } \gamma \\
\mathrm{pg} / \mathrm{ml}\end{array}$ & $\begin{array}{l}\text { IL-12p70 } \\
\mathrm{pg} / \mathrm{ml}\end{array}$ & $\begin{array}{l}\text { IL-6 } \\
\mathrm{pg} / \mathrm{ml}\end{array}$ & $\begin{array}{l}\text { IL-8 } \\
\mathrm{pg} / \mathrm{ml}\end{array}$ & $\begin{array}{l}\text { IL-10 } \\
\mathrm{pg} / \mathrm{ml}\end{array}$ \\
\hline Intercept & $-0.064(0.115)$ & $0.729(0.040)^{* * *}$ & $0.061(0.095)$ & $0.299(0.141)^{*}$ & $0.109(0.076)$ & $0.766(0.053)^{* * *}$ & $0.254(0.112)^{*}$ \\
\hline Age & $<0.001(0.014)$ & $0.013(0.005)^{* *}$ & $0.007(0.011)$ & $0.024(0.019)$ & $0.008(0.010)$ & $0.010(0.006)$ & $0.011(0.015)$ \\
\hline Gender, female & $0.108(0.068)$ & $0.019(0.024)$ & $0.115(0.054)^{*}$ & $0.170(0.100)$ & $0.061(0.049)$ & $0.055(0.031)$ & $0.061(0.077)$ \\
\hline Education & $-0.043(0.030)$ & $-0.003(0.010)$ & $-0.013(0.024)$ & $0.004(0.043)$ & $0.012(0.022)$ & $-0.001(0.014)$ & $-0.025(0.033)$ \\
\hline CVD & $-0.016(0.081)$ & $0.026(0.028)$ & $-0.067(0.065)$ & $0.152(0.107)$ & $0.009(0.056)$ & $0.001(0.038)$ & $0.070(0.083)$ \\
\hline Diabetes & $-0.060(0.107)$ & $0.007(0.036)$ & $0.068(0.084)$ & $-0.152(0.143)$ & $0.004(0.073)$ & $0.060(0.048)$ & $0.086(0.110)$ \\
\hline Health symptoms & $0.030(0.052)$ & $-0.018(0.018)$ & $0.018(0.044)$ & $-0.048(0.064)$ & $-0.006(0.035)$ & $0.023(0.024)$ & $-0.026(0.051)$ \\
\hline Subjective health & $-0.111(0.037)^{* *}$ & $-0.007(0.013)$ & $0.037(0.031)$ & $0.030(0.046)$ & $-0.034(0.025)$ & $-0.014(0.017)$ & $0.039(0.037)$ \\
\hline BMI & $0.013(0.020)$ & $0.001(0.007)$ & $0.003(0.016)$ & $0.007(0.027)$ & $0.027(0.014)$ & -0.007 (0.009) & $<0.001(0.021)$ \\
\hline LDL-C/HDL-C ratio & $0.093(0.039)^{*}$ & $0.008(0.014)$ & $0.031(0.032)$ & $0.006(0.053)$ & $0.050(0.027)$ & $0.006(0.018)$ & $0.021(0.041)$ \\
\hline MAP & 0.009 (0.009) & $<-0.001(0.003)$ & $-0.016(0.007)^{*}$ & $-0.005(0.011)$ & $0.008(0.006)$ & $-0.002(0.004)$ & $0.004(0.009)$ \\
\hline Cholesterol meds & $-0.041(0.060)$ & $0.028(0.021)$ & $0.030(0.050)$ & $0.070(0.080)$ & $0.074(0.041)$ & $0.007(0.028)$ & $0.068(0.062)$ \\
\hline Blood pressure meds & $0.073(0.062)$ & $0.012(0.022)$ & $-0.059(0.051)$ & $-0.114(0.083)$ & $0.009(0.043)$ & $-0.056(0.029)$ & $-0.050(0.065)$ \\
\hline Aspirin & $-0.094(0.067)$ & $-0.010(0.023)$ & $-0.016(0.055)$ & $-0.113(0.079)$ & $-0.007(0.044)$ & $0.040(0.031)$ & $-0.107(0.063)$ \\
\hline Antidepressants & $0.036(0.066)$ & $-0.022(0.023)$ & $0.019(0.055)$ & $-0.115(0.088)$ & $-0.005(0.046)$ & $-0.021(0.031)$ & $-0.132(0.068)$ \\
\hline Ever smoker & $0.007(0.061)$ & $-0.001(0.021)$ & $-0.017(0.049)$ & $0.060(0.084)$ & $0.058(0.043)$ & $-0.028(0.028)$ & $0.028(0.066)$ \\
\hline Physical activity & $-0.014(0.019)$ & $-0.005(0.007)$ & $<-0.001(0.016)$ & $0.016(0.023)$ & $0.012(0.012)$ & $-0.009(0.009)$ & $0.009(0.018)$ \\
\hline Alcohol consumption & $0.012(0.016)$ & $0.010(0.005)$ & $0.025(0.012)^{*}$ & $-0.010(0.020)$ & $0.009(0.011)$ & $0.013(0.007)$ & $<-0.001(0.016)$ \\
\hline Sleep quality & $-0.007(0.030)$ & $0.016(0.010)$ & $0.045(0.024)$ & $0.125(0.039)^{* *}$ & $0.019(0.020)$ & $0.010(0.014)$ & $0.083(0.030)^{* *}$ \\
\hline Negative affect & $0.029(0.017)$ & $-0.003(0.006)$ & $-0.010(0.014)$ & $-0.015(0.021)$ & $-0.003(0.011)$ & $-0.012(0.007)$ & $-0.024(0.016)$ \\
\hline Positive affect & $0.023(0.014)$ & $-0.003(0.005)$ & $<-0.001(0.011)$ & $0.014(0.017)$ & $0.004(0.009)$ & $-0.001(0.006)$ & $0.004(0.014)$ \\
\hline Role overload & $-0.017(0.012)$ & $-0.007(0.004)$ & $0.004(0.010)$ & $-0.005(0.014)$ & $0.003(0.008)$ & $-0.004(0.005)$ & $0.008(0.012)$ \\
\hline Caregiver status & $-0.022(0.093)$ & $0.064(0.032)^{*}$ & $0.013(0.074)$ & $0.039(0.130)$ & $-0.073(0.066)$ & $0.023(0.042)$ & $0.056(0.101)$ \\
\hline Years caregiving & $0.020(0.010)^{*}$ & $-0.002(0.003)$ & $0.006(0.008)$ & $0.015(0.014)$ & $-0.001(0.007)$ & $0.001(0.004)$ & $0.005(0.011)$ \\
\hline Time & $0.066(0.037)$ & $-0.052(0.013)^{* * *}$ & $-0.179(0.032)^{* * *}$ & $-0.246(0.042)^{* * *}$ & $-0.012(0.023)$ & $-0.120(0.017)^{* * *}$ & $-0.014(0.033)$ \\
\hline Placed spouse & $0.058(0.108)$ & $0.022(0.037)$ & $0.034(0.089)$ & $0.133(0.131)$ & $-0.007(0.069)$ & $-0.011(0.050)$ & $0.122(0.100)$ \\
\hline Spouse deceased & $-0.399(0.133)^{* *}$ & $-0.029(0.046)$ & $-0.069(0.109)$ & $0.031(0.152)$ & $0.092(0.085)$ & $-0.022(0.062)$ & $-0.010(0.123)$ \\
\hline Pseudo- $R^{2}$ statistic & $16.97^{* * *}$ & $15.85^{* * *}$ & $16.32^{* * *}$ & $12.82^{* * *}$ & $10.76^{* * *}$ & $19.01^{* * *}$ & $7.02^{* * *}$ \\
\hline
\end{tabular}

Data are given as log-transformed slopes (s.e.); ${ }^{*} \mathrm{p}<0.05 ;{ }^{* *} \mathrm{p}<0.01$; ${ }^{* * *} \mathrm{p}<0.001$. All independent variables were centered to the mean such that the intercepts show the mean biomarker concentrations in the entire sample. Categorical variables were contrast coded as female gender $(+0.5)$ vs. male gender $(-0.5), \mathrm{CVD}(+0.5)$ vs. no CVD $(-0.5)$, diabetes $(+0.5)$ vs. no diabetes $(-0.5)$, medications $(+0.5)$ vs. no medications $(-0.5)$, ever smok- er $(+0.5)$ vs. never smoker $(-0.5)$, and caregiver $(+0.5)$ vs. noncaregiver $(-0.5)$. 'Placed spouse' and 'spouse deceased' indicate the immediate change in the biomarker concentration assessed 3 months after the respective transition. 'Time' indicates the change in the biomarker concentration per each assessment the participant was in the study. cantly associated with changes in levels of any biomarker. However, sICAM-1 levels had significantly dropped at 3 months after the death of the AD spouse ( $\mathrm{p}=0.008$; explained variance $=1.77 \%$ ). Figure $1 \mathrm{~d}$ illustrates that caregivers whose spouse had died had $29 \%$ lower mean sICAM-1 levels than those who continued to provide care for their spouse [230 ng/ml (95\% CI: 170-310) vs. $324 \mathrm{ng} /$ $\mathrm{ml}$ (95\% CI: 278-378)]. The effect of spousal death on sICAM-1 levels remained significant without controlling for covariates $(-0.107 \pm 0.044, \mathrm{p}=0.015)$, and it was not mediated by baseline characteristics that differentiated between caregivers and controls (data not shown). Further exploratory analyses on sICAM-1 yielded significant interactions between death of the $\mathrm{AD}$ spouse and both physical activity $(0.075 \pm 0.033, \mathrm{p}=0.026$; explained variance $=1.25 \%$ ) and the number of health symptoms
$(0.134 \pm 0.065, \mathrm{p}=0.039$; explained variance $=1.05 \%)$. Post hoc probing of these moderating effects showed associations between spousal death and lowered sICAM-1 in caregivers with low physical activity levels $(-0.300 \pm$ $0.087, \mathrm{p}<0.001)$, but not in those with high physical activity levels $(\mathrm{p}=0.41)$, as well as in caregivers with a low number of health symptoms $(-0.257 \pm 0.076, p<0.001)$, but not in those with a high number of health symptoms $(\mathrm{p}=0.17)$.

\section{Discussion}

We found the longer caregivers had been providing care to their AD spouse, the more their CRP levels increased over time. However, being a caregiver per se was 
Fig. 1. Parameters of dementia caregiving stress and changes in biomarker levels. All values are given as multivariate-adjusted geometric means with $95 \%$ CI. a Illustration of the association between duration of caregiving across 5-year steps and change in CRP over time (0 years of caregiving in controls). $\mathbf{b}, \mathbf{d}$ Depictions of lowered CRP and sICAM-1 levels, respectively, in caregivers whose spouse had deceased relative to caregivers who are continuing to provide care for their spouse and controls. c Higher TNF- $\alpha$ levels over time in caregivers compared to controls.

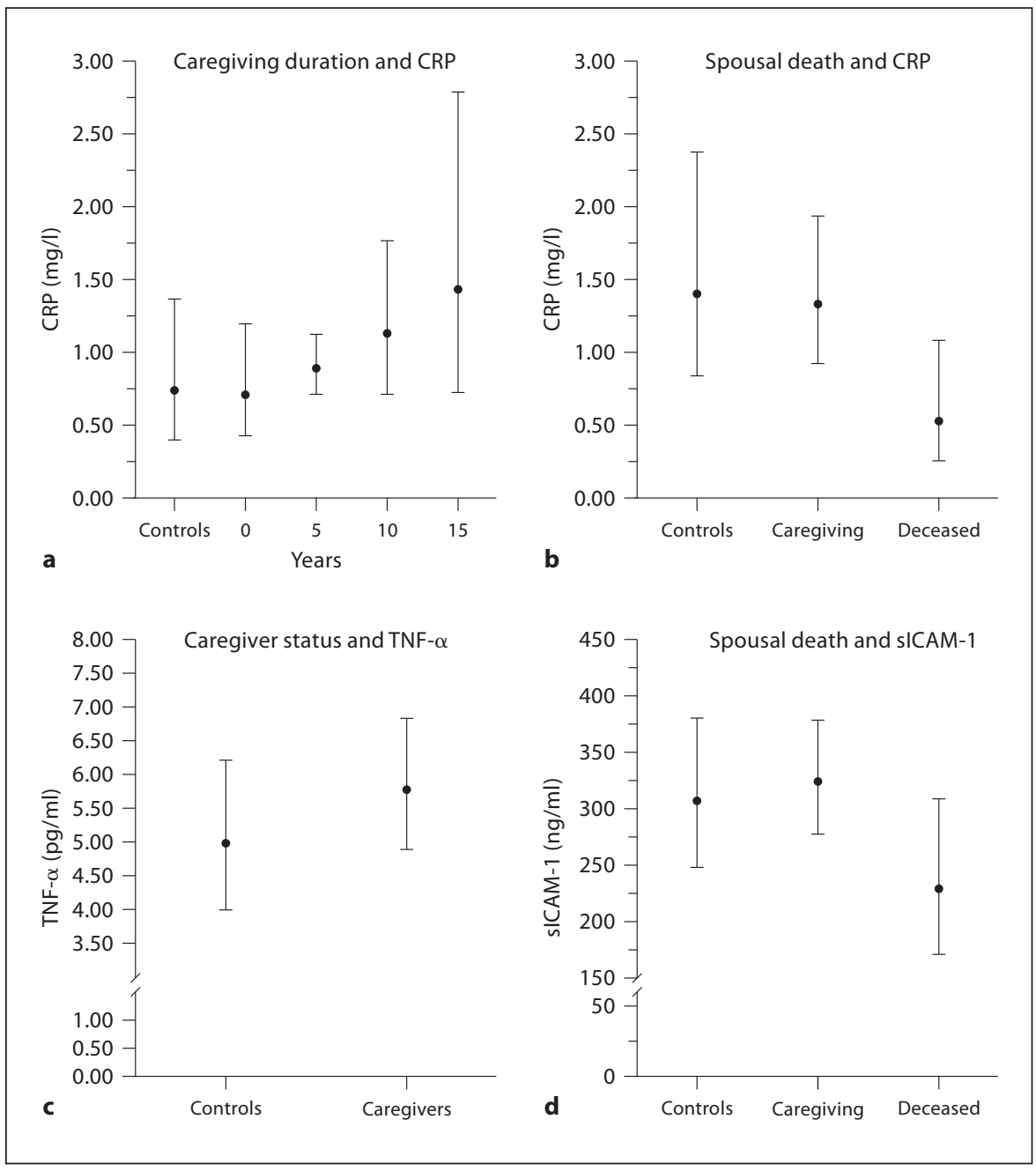

not significantly associated with CRP levels, suggesting that it might be the accumulation of the many factors making up caregiver burden that contributed to increased CRP. AD caregiver burden is understood as the sum of physical, psychological, social, and financial problems that can be experienced by family members caring for a demented relative [52]. Impaired sleep and poor self-care due to restricted time to engage in regular physical activity also contribute to caregiver burden [53]. In agreement with this conceptualization of AD caregiver burden, our caregivers had poorer physical and mental health, and they also slept more poorly and were less physically active than their noncaregiving counterparts at enrolment into the study. Poorer self-rated health, less physical activity, and greater negative affect also showed zero-order correlations with greater CRP levels. Even when taking into account differences in burden-eliciting factors, years of caregiving were associated with CRP levels suggesting that elevated CRP concentration could be an important physical marker of AD caregiver burden itself. Nevertheless, it remains possible that social and financial problems we could not consider for in our analysis accounted for at least part of the increased CRP levels with more years of caregiving. Caregiving strain is associated with increased SAM arousal [20], which could contribute to CRP levels with more years of exposure to caregiving strain, too. A recent study on family caregivers of patients with brain cancer found an increase in both daily output of salivary $\alpha$-amylase (i.e. a marker of sympathetic nervous system activity) and circulating CRP levels sampled over a period of 1 year [54]

Caregiving for a disabled spouse was predictive of CHD [55] and all-cause mortality [56] and elevated CRP concentrations were associated with a greater risk of mor- 
Table 4. Changes over time in circulating biomarkers of endothelial function, cellular adhesion, and hemostasis

\begin{tabular}{|c|c|c|c|c|c|c|}
\hline Variables entered & $\begin{array}{l}\text { Endothelin-1 } \\
\mathrm{pg} / \mathrm{ml}\end{array}$ & $\begin{array}{l}\text { VWF:Ag } \\
\%\end{array}$ & $\begin{array}{l}\text { sICAM-1 } \\
\mathrm{ng} / \mathrm{ml}\end{array}$ & $\begin{array}{l}\text { sVCAM-1 } \\
\mathrm{ng} / \mathrm{ml}\end{array}$ & $\begin{array}{l}\text { D-dimer } \\
\mathrm{ng} / \mathrm{ml}\end{array}$ & $\begin{array}{l}\mathrm{PAI}-1 \\
\mathrm{ng} / \mathrm{ml}\end{array}$ \\
\hline Intercept & $0.044(0.036)$ & $2.157(0.062)^{* * * *}$ & $2.424(0.048)^{* * * *}$ & $2.733(0.043)^{* * * *}$ & $2.863(0.048)^{* * *}$ & $1.515(0.080)^{* * *}$ \\
\hline Age & $0.015(0.005)^{* *}$ & $0.018(0.007)^{*}$ & $-0.005(0.005)$ & $-0.005(0.005)$ & $0.033(0.007)^{* * *}$ & $<-0.001(0.011)$ \\
\hline Gender, female & $0.015(0.025)$ & $-0.015(0.037)$ & $0.014(0.027)$ & $0.002(0.025)$ & $0.033(0.035)$ & $0.051(0.059)$ \\
\hline Education & $0.006(0.011)$ & $-0.015(0.016)$ & $0.003(0.012)$ & $-0.005(0.011)$ & $-0.004(0.015)$ & $-0.014(0.026)$ \\
\hline CVD & $0.013(0.027)$ & $0.097(0.044)^{*}$ & $0.033(0.033)$ & $0.024(0.030)$ & $0.033(0.037)$ & $0.047(0.061)$ \\
\hline Diabetes & $-0.074(0.036)^{*}$ & $-0.011(0.056)$ & $0.002(0.043)$ & $0.003(0.039)$ & $-0.012(0.049)$ & $0.094(0.082)$ \\
\hline Health symptoms & $-0.003(0.016)$ & $-0.027(0.027)$ & $-0.002(0.022)$ & $-0.023(0.019)$ & $-0.003(0.021)$ & $0.015(0.035)$ \\
\hline Subjective health & $-0.001(0.011)$ & $-0.022(0.020)$ & $-0.017(0.015)$ & $-0.016(0.013)$ & $-0.028(0.015)$ & $-0.020(0.026)$ \\
\hline BMI & $0.012(0.007)$ & $0.022(0.011)^{*}$ & $-0.006(0.010)$ & $-0.002(0.007)$ & $-0.007(0.009)$ & $0.054(0.015)^{* * *}$ \\
\hline LDL-C/HDL-C ratio & $0.002(0.013)$ & $0.029(0.021)$ & $0.055(0.016)^{* * *}$ & $0.034(0.014)^{*}$ & $-0.014(0.018)$ & $0.107(0.030)^{* * *}$ \\
\hline MAP & $0.003(0.003)$ & $-0.001(0.005)$ & $0.002(0.004)$ & $-0.001(0.003)$ & $0.005(0.004)$ & $0.021(0.006)^{* * *}$ \\
\hline Cholesterol meds & $0.004(0.020)$ & $0.035(0.033)$ & $0.035(0.025)$ & $0.003(0.022)$ & $0.022(0.027)$ & $0.155(0.045)^{* * *}$ \\
\hline Blood pressure meds & $0.019(0.021)$ & $-0.021(0.033)$ & $0.021(0.025)$ & $0.036(0.023)$ & $0.001(0.028)$ & $0.005(0.047)$ \\
\hline Aspirin & $0.005(0.020)$ & $-0.073(0.035)^{*}$ & $-0.071(0.028)^{*}$ & $-0.050(0.025)^{*}$ & $0.022(0.027)$ & $0.005(0.045)$ \\
\hline Antidepressants & $0.010(0.022)$ & $0.017(0.036)$ & $0.010(0.027)$ & $0.010(0.025)$ & $0.068(0.030)^{*}$ & $0.059(0.050)$ \\
\hline Ever smoker & $-0.036(0.021)$ & $0.014(0.033)$ & $-0.002(0.025)$ & $0.003(0.022)$ & $0.030(0.029)$ & $-0.018(0.049)$ \\
\hline Physical activity & $<-0.001(0.006)$ & $-0.004(0.010)$ & $0.001(0.008)$ & $-0.002(0.007)$ & $-0.006(0.008)$ & $-0.025(0.013)$ \\
\hline Alcohol consumption & $0.006(0.005)$ & $<0.001(0.008)$ & $<0.001(0.006)$ & $0.002(0.006)$ & $-0.009(0.007)$ & $0.027(0.012)^{*}$ \\
\hline Sleep quality & $0.014(0.010)$ & $-0.017(0.016)$ & $-0.002(0.012)$ & $-0.002(0.011)$ & $<-0.001(0.013)$ & $0.007(0.022)$ \\
\hline Negative affect & $-0.001(0.005)$ & $0.009(0.009)$ & $0.009(0.007)$ & $0.011(0.006)$ & $-0.001(0.007)$ & $0.002(0.012)$ \\
\hline Positive affect & $-0.003(0.004)$ & $0.010(0.008)$ & $0.001(0.006)$ & $-0.003(0.005)$ & $-0.007(0.006)$ & $0.016(0.010)$ \\
\hline Role overload & $0.001(0.004)$ & $0.002(0.006)$ & $-0.014(0.005)^{* *}$ & $-0.012(0.004)^{* *}$ & $-0.005(0.005)$ & $0.007(0.008)$ \\
\hline Caregiver status & $-0.027(0.033)$ & $0.056(0.050)$ & $0.023(0.037)$ & $0.018(0.034)$ & $0.015(0.046)$ & $-0.065(0.077)$ \\
\hline Years caregiving & $-0.002(0.004)$ & $-0.008(0.005)$ & $0.001(0.004)$ & $-0.001(0.004)$ & $-0.008(0.005)$ & $0.006(0.008)$ \\
\hline Time & $0.041(0.010)^{* * *}$ & $-0.010(0.019)$ & $0.002(0.016)$ & $0.010(0.015)$ & $-0.026(0.013)$ & $-0.073(0.022)^{* *}$ \\
\hline Placed spouse & $0.041(0.031)$ & $0.021(0.056)$ & $0.027(0.042)$ & $0.035(0.041)$ & $0.005(0.041)$ & $0.058(0.069)$ \\
\hline Spouse deceased & $-0.041(0.040)$ & $-0.066(0.070)$ & $-0.150(0.056)^{* *}$ & $-0.092(0.050)$ & $-0.009(0.050)$ & $0.115(0.083)$ \\
\hline Pseudo- $R^{2}$ statistic & $13.18^{* * *}$ & $10.89^{* * *}$ & $10.24^{* * *}$ & $8.12^{* * *}$ & $22.85^{* * *}$ & $30.36^{* * *}$ \\
\hline
\end{tabular}

Data are given as log transformed slopes (s.e.); ${ }^{*} \mathrm{p}<0.05 ;{ }^{* *} \mathrm{p}<0.01$; ${ }^{* * *} \mathrm{p}<0.001$. All independent variables were centered to the mean such that the intercepts show the mean biomarker concentrations in the entire sample. Categorical variables were contrast coded as female gender $(+0.5)$ vs. male gender $(-0.5)$, CVD $(+0.5)$ vs. no CVD $(-0.5)$, diabetes $(+0.5)$ vs. no diabetes $(-0.5)$, medications $(+0.5)$ vs. no medications $(-0.5)$, ever smok- er $(+0.5)$ vs. never smoker $(-0.5)$, and caregiver $(+0.5)$ vs. noncaregiver $(-0.5)$. 'Placed spouse' and 'spouse deceased' indicate the immediate change in the biomarker concentration assessed 3 months after the respective transition. 'Time' indicates the change in the biomarker concentration per each assessment the participant was in the study. PAI = Plasminogen activator inhibitor; VWF:Ag = von Willebrand factor antigen. tality from vascular and many nonvascular causes [42]. Moreover, even moderately elevated levels of CRP predicted incident frailty in individuals 65 years and older [57]. The relation of AD caregiving duration with CRP levels thus provides one possible pathway leading from chronic caregiving to poor cardiovascular health over time, but also to accelerated decline of physical health across a range of other biological systems. Years of caregiving explained a rather small amount of $1.2 \%$ of the variance in CRP levels over time. However, cutpoints of CRP for low risk ( $<1.0 \mathrm{mg} / \mathrm{l})$, average risk $(1.0-3.0 \mathrm{mg} / \mathrm{l})$, and high risk $(>3.0 \mathrm{mg} / \mathrm{l})$ of $\mathrm{CHD}$ have been defined, whereby the high-risk category has a $\approx 2$-fold increased relative risk compared to the low-risk group [28]. Mean CRP levels were in the low-risk range in controls and in caregivers with shorter duration of caregiving, but in the average-risk range in AD caregivers who had been pro- viding care for 10 years or longer. This effect seems clinically meaningful as caregivers are expected to serve in this role for up to 15 years [2].

We found that death of the AD spouse was associated with a significant drop in caregivers' CRP levels at 3 months post-transition. The same effect could be observed for sICAM-1 levels. The latter may seem an expected finding given that experimental studies found recombinant human CRP induces expression of ICAM-1 in human endothelial cells within $24 \mathrm{~h}$ [58]. The soluble form of ICAM-1 reflects ICAM-1 expression on endothelial cells; ICAM-1 is involved in adherence and subsequent transmigration of circulating leukocytes across the vascular endothelium, thereby promoting inflammation of the coronary artery [59]. Underscoring the clinical value of sICAM-1 as a cardiovascular biomarker, elevated levels of sICAM-1 were prospectively associated with the 
risk of first-time myocardial infarction in apparently healthy men [60]. Reduction in sICAM-1 was particularly seen in caregivers with fewer health symptoms and in those with lower physical activity levels at 3 months after spousal death. Although speculative, lowered sICAM1 might mirror a reduction in health symptoms, as sICAM-1 is increased in many pathological conditions [61]. Moreover, as sICAM-1 increases with exercise [62], sICAM-1 might have been less detectable in the blood of poor exercisers. The decrease in CRP and sICAM-1 levels following the death of the AD spouse could reflect a lessening of cardiovascular burden with $\mathrm{AD}$ caregiving. This seems a clinically meaningful effect. For instance, on a population-based level, statin use is associated with a $12 \%$ lower CRP level than nonuse [63], whereas caregivers whose spouse had died had a $60 \%$ lower mean CRP level compared to those who continued to provide care. Moreover, continued care was associated with CRP levels in the average risk range for $\mathrm{CHD}$, whereas, after spousal death, caregivers' mean CRP levels fell into the low-risk range. Nevertheless, although these effects are intriguing, it should be noted that a large bereavement literature actually suggests that morbidity and mortality risk, including from cardiovascular causes, increases in the early months after partner loss [64].

Placement of the AD spouse in a long-term care facility did not significantly affect CRP levels, likely because the biobehavioral responses to spousal death are different from those elicited by placement of an AD spouse. For instance, in caregivers who were strained prior to the death of their spouse, the death itself did not increase their level of distress, but instead reduced health risk behaviors [65]. In contrast, while some burdens are lessened when a spouse is placed, others persist, or may even increase [66]. For instance, caregivers may stay involved in physical care during their visits and worry about the adequacy of treatment for the loved one and financial costs.

Relative to controls, caregivers showed higher levels of the proinflammatory cytokine TNF- $\alpha$ over time. This finding adds to the notion of an inflammatory state in $\mathrm{AD}$ caregivers [4]. However, except for TNF- $\alpha$, we did not find a significant association between caregiver status and circulating levels of any other biomarker, including CRP. Several explanations may apply to this observation. We controlled for possible confounders of biomarker levels, including medication use, lifestyle, and sleep quality, all of which showed associations with some biomarkers (table 3, 4). Assessment of biomarkers only 3 months after a major transition in the caregiving situation might have been too early to detect significant changes in some bio- markers. Most of the spouses suffered mild-to-moderate dementia. A greater proportion of spouses with severe dementia might have evoked greater caregiving stress with changes in biomarkers downstream. Healthier individuals are more likely to become caregivers and to remain in this role. Such a healthy caregiver effect might partially prevent biomarker changes in stressful situations. This notion is supported by the observation that covariates indicating compromised physical and mental health in caregivers did not turn out to moderate or mediate the caregiver-biomarker relationship.

The longitudinal design with an average of three assessments per participant, relatively few missing followup data, and adjustment for important confounding variables are all strengths of our study. However, the study also has its limitations. We are unable to make a statement about the trajectory in biomarker levels beyond the 3-month post-transition changes because we had too few data points available to reliably estimate post-transition slopes in biomarker concentrations. The ultimate health consequences of the changes in CRP levels in AD caregivers remain to be determined. Moreover, our findings might not generalize to populations of younger AD caregivers, those with a greater proportion of male caregivers, and $\mathrm{AD}$ caregivers with greater impairments in physical health.

Taken together, we found that longer duration of caregiving and caregiver status were associated with increased CRP and TNF- $\alpha$ levels, respectively, with both these associations suggesting a proinflammatory state. In contrast, death of the AD spouse was associated with a decrease in inflammation-related biomarkers, namely in CRP and sICAM-1. Chronic caregiving stress is associated with SAM arousal [20], and CRP, TNF- $\alpha$, and sICAM-1 are responsive to chronic stress [67]. Therefore, cessation of caregiving stress and of the accompanying SAM arousal after spousal death could have favorably affected caregivers' proinflammatory state. CRP might be a biomarker that well integrates several cardiovascular processes that are responsive to changes in caregiving burden. This would make CRP a promising candidate for the longitudinal investigation of atherothrombotic consequences of chronic $\mathrm{AD}$ caregiving.

\section{Acknowledgements}

The authors wish to thank Susan Calleran and Christine Gonzaga for data collection. The study was supported by NIH/NIA award AG 15301 to Igor Grant, and additionally by awards AG 03090 to Brent Mausbach and AG 08415 to Sonia Ancoli-Israel. 


\section{References}

1 Schulz R, O’Brien AT, Bookwala J, Fleissner $\mathrm{K}$ : Psychiatric and physical morbidity effects of dementia caregiving: prevalence, correlates, and causes. Gerontologist 1995;35:771791.

-2 Vitaliano PP, Zhang J, Scanlan JM: Is caregiving hazardous to one's physical health? A meta-analysis. Psychol Bull 2003;129:946-972.

-3 Schulz R, Martire LM: Family caregiving of persons with dementia: prevalence, health effects, and support strategies. Am J Geriatr Psychiatry 2004;12:240-249.

4 Gouin JP, Hantsoo L, Kiecolt-Glaser JK: Immune dysregulation and chronic stress among older adults: a review. Neuroimmunomodulation 2008;15:251-259.

5 von Känel R, Mausbach BT, Patterson TL, Dimsdale JE, Aschbacher K, Mills PJ, Ziegler MG, Ancoli-Israel S, Grant I: Increased Framingham Coronary Heart Disease Risk Score in dementia caregivers relative to noncaregiving controls. Gerontology 2008;54 131-137.

6 Mausbach BT, Roepke SK, Ziegler MG, Milic M, von Känel R, Dimsdale JE, Mills PJ, Patterson TL, Allison MA, Ancoli-Israel S, Grant I: Association between chronic caregiving stress and impaired endothelial function in the elderly. J Am Coll Cardiol 2010;55 2599-2606.

7 Roepke SK, Allison M, von Känel R, Mausbach BT, Chattillion EA, Harmell AL, Patterson TL, Dimsdale JE, Mills PJ, Ziegler MG, Ancoli-Israel S, Grant I: Relationship between chronic stress and carotid intimamedia thickness (IMT) in elderly Alzheimer's disease caregivers. Stress 2011, E-pub ahead of print.

8 Aschbacher K, von Känel R, Dimsdale JE, Patterson TL, Mills PJ, Mausbach BT, Allison MA, Ancoli-Israel S, Grant I: Dementia severity of the care receiver predicts procoagulant response in Alzheimer caregivers. Am J Geriatr Psychiatry 2006;14:694-703.

$>9$ Adams KB: Specific effects of caring for a spouse with dementia: differences in depressive symptoms between caregiver and noncaregiver spouses. Int Psychogeriatr 2008; 20:508-520.

$\checkmark 10$ McCurry SM, Logsdon RG, Teri L, Vitiello MV: Sleep disturbances in caregivers of persons with dementia: contributing factors and treatment implications. Sleep Med Rev 2007; 11:143-153.

$\checkmark 11$ Rozanski A, Blumenthal JA, Davidson KW, Saab PG, Kubzansky L: The epidemiology, pathophysiology, and management of psychosocial risk factors in cardiac practice: the emerging field of behavioral cardiology. J Am Coll Cardiol 2005;45:637-651.

- 12 Mausbach BT, Patterson TL, Rabinowitz YG Grant I, Schulz R: Depression and distress predict time to cardiovascular disease in dementia caregivers. Health Psychol 2007;26: 539-544.
13 von Känel R, Ancoli-Israel S, Dimsdale JE, Mills PJ, Mausbach BT, Ziegler MG, Patterson TL, Grant I: Sleep and biomarkers of atherosclerosis in elderly Alzheimer caregivers and controls. Gerontology 2010;56:41-50.

14 Mausbach BT, von Känel R, Aschbacher K, Roepke SK, Dimsdale JE, Ziegler MG, Mills PJ, Patterson TL, Ancoli-Israel S, Grant I: Spousal caregivers of patients with Alzheimer's disease show longitudinal increases in plasma level of tissue-type plasminogen activator antigen. Psychosom Med 2007;69: 816-822.

15 Vitaliano PP, Scanlan JM, Zhang J, Savage MV, Hirsch IB, Siegler IC: A path model of chronic stress, the metabolic syndrome, and coronary heart disease. Psychosom Med 2002;64:418-435.

- 16 von Känel R, Dimsdale JE, Mills PJ, AncoliIsrael S, Patterson TL, Mausbach BT, Grant I: Effect of Alzheimer caregiving stress and age on frailty markers interleukin-6, C-reactive protein, and D-dimer. J Gerontol A Biol Sci Med Sci 2006;61:963-969.

17 Kiecolt-Glaser JK, Preacher KJ, MacCallum RC, Atkinson C, Malarkey WB, Glaser R: Chronic stress and age-related increases in the proinflammatory cytokine IL-6. Proc Natl Acad Sci USA 2003;100:9090-9095.

18 Kim MD, Hong SC, Lee CI, Kim SY, Kang IO, Lee SY: Caregiver burden among caregivers of Koreans with dementia. Gerontology 2009;55:106-113.

19 Mausbach BT, Aschbacher K, Patterson TL von Känel R, Dimsdale JE, Mills PJ, AncoliIsrael S, Grant I: Effects of placement and be reavement on psychological well being and cardiovascular risk in Alzheimer's caregivers: a longitudinal analysis. J Psychosom Res 2007;62:439-445.

20 Grant I: Caregiving may be hazardous to your health. Psychosom Med 1999;61:420-423.

21 Roepke SK, Chattillion EA, von Känel R, Allison M, Ziegler MG, Dimsdale JE, Mills PJ, Patterson TL, Ancoli-Israel S, Calleran S, Harmell AL, Grant I: Carotid plaque in Alzheimer caregivers and the role of sympathoadrenal arousal. Psychosom Med 2011;73: 206-213.

22 von Känel R, Mausbach BT, Dimsdale JE, Mills PJ, Patterson TL, Ancoli-Israel S, Ziegler MG, Roepke SK, Harmell AL, Allison M, Grant I: Regular physical activity moderates cardiometabolic risk in Alzheimer's caregivers. Med Sci Sports Exerc 2011; 43:181-189.

23 Vitaliano PP, Persson R, Kiyak A, Saini H, Echeverria D: Caregiving and gingival symptom reports: psychophysiologic mediators. Psychosom Med 2005;67:930-938.

24 Khot UN, Khot MB, Bajzer CT, Sapp SK, Ohman EM, Brener SJ, Ellis SG, Lincoff AM, Topol EJ: Prevalence of conventional risk factors in patients with coronary heart disease. JAMA 2003;290:898-904.
25 Ridker PM, Brown NJ, Vaughan DE, Harrison DG, Mehta JL: Established and emerging plasma biomarkers in the prediction of first atherothrombotic events. Circulation 2004; 109(25 suppl 1):IV6-IV19.

26 Koenig W: Cardiovascular biomarkers: added value with an integrated approach? Circulation 2007;116:3-5.

27 C Reactive Protein Coronary Heart Disease Genetics Collaboration (CCGC), Wensley F, Gao P, Burgess S, Kaptoge S, Di Angelantonio E, Shah T, Engert JC, Clarke R, DaveySmith G, Nordestgaard BG, Saleheen D, Samani NJ, Sandhu M, Anand S, Pepys MB, Smeeth L, Whittaker J, Casas JP, Thompson SG, Hingorani AD, Danesh J: Association between $\mathrm{C}$ reactive protein and coronary heart disease: mendelian randomisation analysis based on individual participant data. BMJ 2011;342:d548.

-28 Pearson TA, Mensah GA, Alexander RW, Anderson JL, Cannon RO 3rd, Criqui M, Fadl YY, Fortmann SP, Hong Y, Myers GL, Rifai N, Smith SC Jr, Taubert K, Tracy RP, Vinicor F, Centers for Disease Control and Prevention, American Heart Association: Markers of inflammation and cardiovascular disease: application to clinical and public health practice: a statement for healthcare professionals from the Centers for Disease Control and Prevention and the American Heart Association. Circulation 2003;107: 499-511.

29 Tracy RP, Lemaitre RN, Psaty BM, Ives DG, Evans RW, Cushman M, Meilahn EN, Kuller LH: Relationship of C-reactive protein to risk of cardiovascular disease in the elderly: results from the Cardiovascular Health Study and the Rural Health Promotion Project. Arterioscler Thromb Vasc Biol 1997;17: 1121-1127.

30 Mahmoudi M, Curzen N, Gallagher PJ: Atherogenesis: the role of inflammation and infection. Histopathology 2007;50:535-546.

-31 Sarwar N, Thompson AJ, Di Angelantonio E: Markers of inflammation and risk of coronary heart disease. Dis Markers 2009;26: 217-225.

-32 McKellar GE, McCarey DW, Sattar N, McInnes IB: Role for TNF in atherosclerosis? Lessons from autoimmune disease. Nat Rev Cardiol 2009;6:410-417.

-33 Schroecksnadel K, Frick B, Winkler C, Fuchs D: Crucial role of interferon-gamma and stimulated macrophages in cardiovascular disease. Curr Vasc Pharmacol 2006;4:205213.

34 Zhou RH, Shi Q, Gao HQ, Shen BJ: Changes in serum interleukin-8 and interleukin-12 levels in patients with ischemic heart disease in a Chinese population. J Atheroscler Thromb 2001;8:30-32.

-35 Apostolakis S, Vogiatzi K, Amanatidou V, Spandidos DA: Interleukin 8 and cardiovascular disease. Cardiovasc Res 2009;84:353-360. 
\$6 Lakoski SG, Liu Y, Brosnihan KB, Herrington DM: Interleukin-10 concentration and coronary heart disease (CHD) event risk in the estrogen replacement and atherosclerosis (ERA) study. Atherosclerosis 2008;197: 443-447.

37 Thorin E, Webb DJ: Endothelium-derived endothelin-1. Pflugers Arch 2010;459:951958.

38 Paulinska P, Spiel A, Jilma B: Role of von Willebrand factor in vascular disease. Hamostaseologie 2009;29:32-38.

-39 Hope SA, Meredith IT: Cellular adhesion molecules and cardiovascular disease. Part II. Their association with conventional and emerging risk factors, acute coronary events and cardiovascular risk prediction. Intern Med J 2003;33:450-462.

-40 Vaughan DE: PAI-1 and atherothrombosis. J Thromb Haemost 2005;3:1879-1883.

-41 Lowe GD: Fibrin D-dimer and cardiovascular risk. Semin Vasc Med 2005;5:387-398.

42 Emerging Risk Factors Collaboration, Kaptoge S, Di Angelantonio E, Lowe G, Pepys MB, Thompson SG, Collins R, Danesh J: Creactive protein concentration and risk of coronary heart disease, stroke, and mortality: an individual participant meta analysis. Lancet 2010;375:132-140.

43 Smith NL, Psaty BM, Furberg CD, White R, Lima JA, Newman AB, Manolio TA: Temporal trends in the use of anticoagulants among older adults with atrial fibrillation. Arch Intern Med 1999;159:1574-1578.

44 Topolski TD, LoGerfo J, Patrick DL, Williams B, Walwick J, Patrick MB: The Rapid Assessment of Physical Activity (RAPA) among older adults. Prev Chronic Dis 2006; 3:A118.

45 Buysse DJ, Reynolds CF 3rd, Monk TH, Hoch CC, Yeager AL, Kupfer DJ: Quantification of subjective sleep quality in healthy elderly men and women using the Pittsburgh Sleep Quality Index (PSQI). Sleep 1991;14: 331-338.

$\checkmark 46$ Watson D, Clark LA, Tellegen A: Development and validation of brief measures of positive and negative affect: The PANAS scales. J Pers Soc Psychol 1988:54:1063-1070.
47 Pearlin LI, Mullan JT, Semple SJ, Skaff MM: Caregiving and the stress process: an overview of concepts and their measures. Gerontologist 1990;30:583-594.

48 Morris JC: The Clinical Dementia Rating (CDR): current version and scoring rules. Neurology 1993;43:2412-2414.

49 Singer JD, Willett JB: Applied longitudinal data analysis: modelling change and event occurrence. New York, Oxford University Press, 2003.

50 Kraemer HC, Blasey CM: Centring in regression analyses: a strategy to prevent errors in statistical inference. Int J Methods Psychiatr Res 2004;13:141-151.

51 Holmbeck GN: Post-hoc probing of significant moderational and mediational effects in studies of pediatric populations. J Pediatr Psychol 2002;27:87-96.

52 George LK, Gwyther LP: Caregiver well-being: a multidimensional examination of family caregivers of demented adults. Gerontologist 1986;26:253-259.

53 Kaufer DI, Borson S, Kershaw P, Sadik K: Reduction of caregiver burden in Alzheimer's disease by treatment with galantamine. CNS Spectr 2005; 10:481-488.

54 Rohleder N, Marin TJ, Ma R, Miller GE: Biologic cost of caring for a cancer patient: dysregulation of pro- and anti-inflammatory signaling pathways. J Clin Oncol 2009;27: 2909-2915.

55 Lee S, Colditz GA, Berkman LF, Kawachi I: Caregiving and risk of coronary heart disease in U.S. women: a prospective study. Am J Prev Med 2003;24:113-119.

56 Schulz R, Beach SR: Caregiving as a risk factor for mortality: the Caregiver Health Effects Study. JAMA 1999;282:2215-2219.

57 Puts MT, Visser M, Twisk JW, Deeg DJ, Lips P: Endocrine and inflammatory markers as predictors of frailty. Clin Endocrinol (Oxf) 2005;63:403-411.
Pasceri V, Willerson JT, Yeh ET: Direct proinflammatory effect of C-reactive protein on human endothelial cells. Circulation 2000; 102:2165-2168.

59 Leeuwenberg JF, Smeets EF, Neefjes JJ, Shaffer MA, Cinek T, Jeunhomme TM, Ahern TJ, Buurman WA: E-selectin and intercellular adhesion molecule-1 are released by activated human endothelial cells in vitro. Immunology 1992;77:543-549.

60 Ridker PM, Hennekens CH, Roitman-Johnson B, Stampfer MJ, Allen J: Plasma concentration of soluble intercellular adhesion molecule 1 and risks of future myocardial infarction in apparently healthy men. Lancet 1998; 351:88-92.

61 Witkowska AM, Borawska MH: Soluble intercellular adhesion molecule-1 (sICAM-1): an overview. Eur Cytokine Netw 2004;15: 91-98.

62 Rehman J, Mills PJ, Carter SM, Chou J, Thomas J, Maisel AS: Dynamic exercise leads to an increase in circulating ICAM-1: further evidence for adrenergic modulation of cell adhesion. Brain Behav Immun 1997; 11:343-551.

63 Lyngdoh T, Vollenweider P, Waeber G, Marques-Vidal P: Association of statins with inflammatory cytokines: a populationbased Colaus study. Atherosclerosis 2011, Epub ahead of print.

64 Stroebe M, Schut H, Stroebe W: Health outcomes of bereavement. Lancet 2007;370: 1960-1973.

65 Schulz R, Beach SR, Lind B, Martire LM, Zdaniuk B, Hirsch C, Jackson S, Burton L: Involvement in caregiving and adjustment to death of a spouse: findings from the caregiver health effects study. JAMA 2001;285: 3123-3129.

66 Schulz R, Belle SH, Czaja SJ, McGinnis KA, Stevens A, Zhang S: Long-term care placement of dementia patients and caregiver health and well-being. JAMA 2004;292:961967.

-67 Hänsel A, Hong S, Cámara RJ, von Känel R: Inflammation as a psychophysiological biomarker in chronic psychosocial stress. Neurosci Biobehav Rev 2010;35:115-121. 